\title{
PERENCANAAN PRELOADING DENGAN PENGGUNAAN PREFABRICATED VERTICAL DRAIN UNTUK PERBAIKAN TANAH LUNAK PADA JALAN TOL PEJAGAN-PEMALANG
}

\author{
Athaya Zhafirah, Dewi Amalia \\ Jurusan Teknik Sipil \\ Politeknik Negeri Bandung Jl. Gegerkalong Hilir Ds.Ciwaruga Kotak pos 1234 Bdg 40012 \\ Email: azhafirah.AZ@gmail.com
}

\begin{abstract}
ABSTRAK
Jalan Tol Pejagan-Pemalang merupakan bagian dari jaringan Jalan Tol Trans Jawa yang menjadi solusi dari permasalahan kemacetan di Jalur Pantai Utara (Pantura). Jalan Tol Pejagan-Pemalang berada di atas tanah lunak yang akan menimbulkan permasalahan geoteknik, seperti daya dukung tanah dasar yang rendah, stabilitas timbunan, dan penurunan yang besar serta berlangsung dalam jangka waktu yang lama. Tanah dasar yang lunak tersebut tidak mampu untuk menahan beban total timbunan rencana yaitu $8,9 \mathrm{~m}$. Tinggi timbunan maksimum yang mampu ditahan oleh tanah dasar tersebut adalah $5 \mathrm{~m}$. Dengan memperhatikan penurunan total yang terjadi, tinggi timbunan pada saat pelaksanaan harus lebih tinggi dari tinggi timbunan rencana. Tinggi timbunan pada saat pelaksanaan akhir adalah $11 \mathrm{~m}$ dengan penurunan total yang terjadi sebesar 2,122 m dalam waktu 38,49 tahun. Masalah ini dapat diatasi dengan memperbaiki tanah dasar menggunakan PVD yang dioptimalkan dengan preloading. PVD adalah lembaran plastik untuk drainase vertikal yang panjang berbahan komposit, terdiri dari drain core dan filter jacket. Dari hasil perencanaan, PVD yang digunakan adalah tipe Ce-Teau Drain CT-882 dengan pola segiempat jarak 1,2 $\mathrm{m}$ sedalam $10 \mathrm{~m}$ dari muka tanah asli. Penimbunan dilakukan bertahap dengan kecepatan penimbunan $1 \mathrm{~m}$ perminggu. Waktu yang dibutuhkan untuk mencapai penurunan total sebesar 2,122 m dengan metode preloading kombinasi PVD adalah 11 minggu.Biaya yang dibutuhkan untuk melakukan pekerjaan penimbunan dan pemasangan PVD sesuai dengan desain adalah Rp. 3.446.349.317,-.
\end{abstract}

Kata kunci: konsolidasi, PVD, daya dukung tanah dasar, stabilitas, timbunan

\section{PENDAHULUAN}

Transportasi darat memiliki peranan penting dalam sektor perhubungan. Salah satu prasarana transportasi darat yang sangat penting adalah jalan. Salah satu jalan yang menjadi tumpuan utama arus kendaraan pribadi dan distribusi logistik nasional di sepanjang Pulau Jawa adalah jalur Pantura. Saat ini jalur Pantura sudah tidak dapat menampung kendaraan yang terus meningkat setiap tahunnya. Solusi untuk mengurangi permasalahan tersebut adalah membangun Jalan Tol Pejagan-Pemalang.

Tanah dasar pada lokasi kajian berada di atas tanah lunak yang memiliki sifat cenderung sangat compressible, tahanan geser rendah, permeabilitasrendah, dan daya dukung rendah. Tanah dasar tersebut hanya mampu menahan beban timbunan 5m, sedangkan tinggi timbunan yang seharusnya dilaksanakan di lapangan $11 \mathrm{~m}$.

Dengan adanya beban timbunan $11 \mathrm{~m}$, tanah dasar mengalami penurunan yang besar sedalam 2,122 m dalam jangka waktu 38,49 tahun. Oleh karena itu, perlu dilakukan perbaikan dengan menggunakan PVD yang dikombinasikan dengan preloading.
Lokasi Jalan Tol Pejagan-Pemalang dilihat pada Gambar 1.

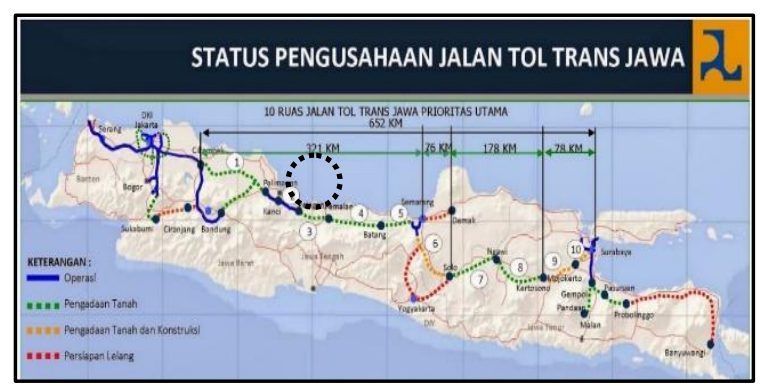

Gambar 1. Lokasi Kajian

\section{STUDIPUS TAKA}

Penambahan beban di atas permukaan tanah lunak yang memiliki daya dukung yang rendah akan menyebabkan lapisan tanah di bawahnya mengalami pemampatan yang besar serta berlangsung dalamjangka waktu yang lama, serta permasalahan daya dukung (stabilitas terhadap puncture) dan kelongsoran timbunan (stabilitas rotational). Pemampatan tersebut disebabkan oleh adanya keluarnya air (pemampatan konsolidasi/consolidation settlement) atau udara 
(pemampatan seketika/immediate settlement) dari dalam pori. Keadaan tanah dasar yang demikian akan mempengaruhi kondisi badan jalan di atasnya dan akan mempercepat kerusakan jalan tersebut dengan terjadinya perbedaan penurunan (differential setllement). Maka dari itu, perlu dilakukan suatu upaya perbaikan tanah.

\subsection{Daya Dukung}

Daya dukung adalah kemampuan tanah menahan beban, seperti beban timbunan, beban perkerasan, beban timbunan, dan beban lalu lintas. Analisis daya dukung menggunakan analisis stabilitas terhadap puncture yang pada prinsipnya sama dengan perhitungan daya dukung pondasi dangkal di kondisi yang paling kritis (short term). Untuk menganalisis daya dukung tanah menggunakan Persamaan 1 (Wahyudi, 1997).

$\mathrm{FK}=\frac{(\pi+2) \times \mathrm{Cu}}{\gamma_{\text {timb }} \times \mathrm{H}_{\text {timb }}}$

$\mathrm{Cu} \quad$ : kohesi

$\gamma_{\text {timb }}:$ berat isi timbunan

$\left(\mathrm{t} / \mathrm{m}^{3}\right)$

$\mathrm{H}_{\mathrm{timb}}$ : tinggi timbunan

(m)

\subsection{Stabilitas Timbunan}

Stabilitas timbunan terhadap rotational pada perencanaan ini menggunakan bantunan software GeoStudio 2007 Slope/W.

\subsection{Penurunan Seketika}

Penurunan seketika terjadi seketika saat beban diletakkan di atas tanah, penambahan beban tersebut menimbulkan tegangan tekan yang menyebabkan tanah terkompresi ke arah vertikal dan penurunan yang terjadi akan diikuti oleh pergerakan tanah ke arah lateral dan secara keseluruhan tidak akan mengalami perubahan volume tanah. Untuk menghitung penurunan seketika menggunakan Persamaan 2 (Giroud, 1973).

$\mathrm{Si}=\mathrm{q} \sum \mathrm{i}\left(\frac{\mathrm{h}}{\mathrm{E}^{\prime}}\right)$

$\mathrm{Si}$ : penurunan seketika

(m)

q : tegangan permukaan

$\left(\mathrm{t} / \mathrm{m}^{2}\right)$

h : tebal lapisan tanah $\mathrm{i}$

(m)

E' : modulus oedometrik

$$
E=\frac{E}{\left(1-\frac{2 \mu^{2}}{1-\mu}\right)}
$$

E : modulus elastisitas

$\mu \quad$ : koefisien poisson

\subsection{Penurunan Konsolidasi}

Penurunan konsolidasi merupakan keadaan apabila lapisan tanahmengalami penambahan beban, tekanan air pori akan naik secara mendadak. Keluarnya air pori disertai dengan berkurangnya volume tanah yang menyebabkan penurunan lapisan tanah. Pada tanah lempung yang berpemeabilitas rendah, tegangan air pori berlebih memerlukan waktu yang lama untuk terdisipasi, dengan demikian penurunan konsolidasi membutuhkan waktu yang sangat lama. Untuk menghitung penurunan konsolidasi meng gunakan Persamaan 3 (Das, 1985).

$\mathrm{Sc}=\sum\left[\frac{\mathrm{C}_{\mathrm{c}} \times \mathrm{h}}{1+\mathrm{e}} \times \log \left(\frac{\sigma_{\mathrm{o}}+\Delta \sigma}{\sigma_{0}}\right)\right]$

Sc : penurunan konsolidasi

(m)

$\mathrm{Cc}$ : indeks pemampatan

h : tebal lapisan tanah

(m)

e : angka pori

$\sigma_{\mathrm{o}}:$ tekanan tanah efektif

$\left(\mathrm{t} / \mathrm{m}^{2}\right)$

$\Delta \sigma:$ tambahan tekanan efektif

$\left(\mathrm{t} / \mathrm{m}^{2}\right)$

\subsection{Waktu Penurunan Konsolidasi}

Waktu penurunan merupakan parameter penting dalam memprediksi penurunan konsolidasi dan yang mempengaruhi waktu penurunan adalah panjang aliran yang dilalui air pori untuk terdisipasi. Dikarenakan permeabilitas tanah lunak kecil, penurunan konsolidasi akan selesai dalam jangka waktu yang lama dan bisa lebih lama dari umur rencana konstruksi. Untuk menghitung waktu penurunan menggunakan Persamaan 4 (Terzaghi, 1990).

$\mathrm{t}=\frac{\mathrm{T}_{\mathrm{v}} \times \mathrm{H}_{\mathrm{dr}}{ }^{2}}{\mathrm{Cv}}$

t : waktu

(tahun)

$\mathrm{T}_{\mathrm{v}}$ : faktor waktu

$\mathrm{H}_{\mathrm{dr}}$ : panjang aliran

$\mathrm{Cv}$ : koef. konsolidasi

(m)

Jika lapisan tanah homogen dan mempunyai beberapa nilai $\mathrm{Cv}$, maka harga $\mathrm{Cv}$ yang digunakan adalah dengan menggunakan Persamaan 5 (ABSI, 1965).

$\mathrm{CV}_{\text {Rata-rata }}=\frac{\mathrm{z}^{2}}{\left(\left(\frac{\mathrm{h}_{1}}{\sqrt{\mathrm{Cv}_{1}}}\right)+\left(\frac{\mathrm{h}_{2}}{\sqrt{\mathrm{Cv}_{2}}}\right)+\cdots+\left(\frac{\mathrm{h}_{\mathrm{i}}}{\sqrt{\mathrm{Cv}_{\mathrm{i}}}}\right)\right)^{2}}$
$\mathrm{Z} \quad$ : tebal tanah

$\mathrm{h}_{\mathrm{i}} \quad$ : tebal lapisan

$\mathrm{Cv}_{\mathrm{i}}: \mathrm{Cv}$ lapisan-i (m)

$(\mathrm{m})$ $\left(\mathrm{m}^{2} / \mathrm{thn}\right)$ 


\subsection{Tinggi Timbunan Pelaksanaan}

Tinggi timbunan pada saat pelaksanaan di lapangan tidak akan sama dengan tinggi timbunan rencana. Untuk muka air tanah (MAT) yang berada di elevasi \pm 0.00 tanah dasar, timbunan yang mengalami penurunan akan mengalami perubahan berat karena selama terjadi penurunan sebagian tanah timbunan berada di bawah muka air tanah, dapatdiligat pada Gambar 2.

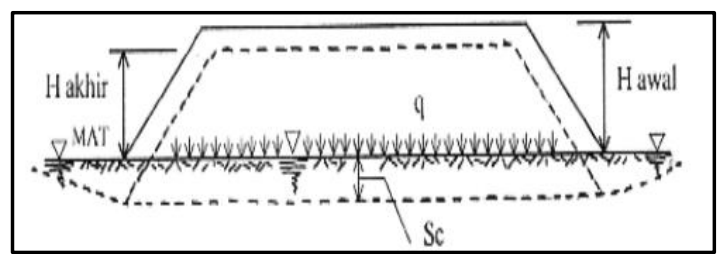

Gambar 2. Tinggi Timbunan Pelaksanaan

Untuk menghitung tinggi timbunan pelaksanaan menggunakan Persamaan 6 (Mochtar, 2000).

$\mathrm{H}_{\text {Inisial }}=\frac{\mathrm{q}_{\text {Timbunan }}+\left(\mathrm{Sc} \times \gamma_{\text {Timb }}\right)+\left(\mathrm{Sc} \times \gamma^{\prime}\right)}{\gamma_{\text {Timb }}}$

$\mathrm{H}_{\text {inisial }}$ : tinggi timbunan pelaksanaan

(m)

$\mathrm{q}_{\text {final }}$ : beban timbunan

$\left(\mathrm{t} / \mathrm{m}^{2}\right)$

Sc : penurunan

$\gamma_{\text {Timb }}:$ berat isi timbunan

$(\mathrm{m})$

$\left(\mathrm{t} / \mathrm{m}^{3}\right)$

$\gamma^{\prime} \quad$ : berat isi efektif

$\gamma^{\prime}=\gamma_{\text {Timbunan }}-\gamma_{\mathrm{w}}$

$\gamma_{\mathrm{w}}=$ berat isi air $=1 \mathrm{t} / \mathrm{m}^{3}$

$\left(\mathrm{t} / \mathrm{m}^{3}\right)$

$\left(\mathrm{t} / \mathrm{m}^{3}\right)$

\section{Preloading}

Preloading adalah beban sementara yang diletakkan pada suatu lahan konstruksi, yang berfungsi untuk mengoptimalkan kinerja PVD dan untuk memperbaiki kondisi daya dukung tanah dasar dimana konstruksi akan didirikan. Preloading yang paling sederhana adalah dengan menggunakan tanah timbunan.

\section{Prefabricated Vertical Drain (PVD)}

Waktu terjadinya penurunan berlangsung dalam waktu yang cenderung sangat lama. Prefabricated Vertical Drain (PVD) digunakan untuk mempercepat laju penurunan konsolidasi dengan cara memperpendek lintasan pengaliran dalam lempung. Ukuran PVD yang umum digunakan adalah lebar $100 \mathrm{~mm}$, dengan tebal $3-7 \mathrm{~mm}$. Terdiri dari bagian luar sebagai filter jacket dan drain core (bagian inti sebagai tempat air pori mengalir). Fungsi dari filter jacket sebagai filter untuk membatasi masuknya butiran-butiran tanah halus yang akan menghalangi jalannya pengaliran air. Sedangkan fungsi dari drain core adalah sebagai jalannya aliran, me mastikan jalannya aliran yang lurus vertikal, dan sifatnya yang kaku memberikan kekuatan terhadap tekanan horisontal dan aliran. Bagian PVD dapat dilihat pada Gambar 3.

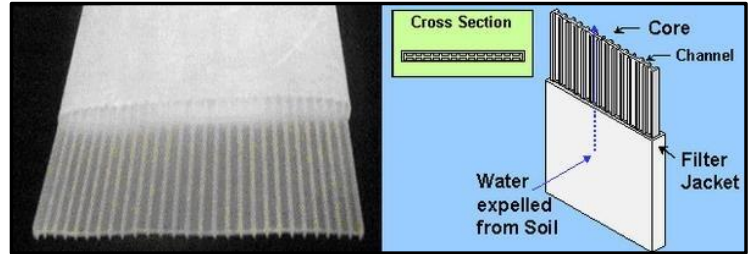

Gambar 3. Bagian PVD

Perhitungan penentuan waktu penurunan tanah dasar dengan PVD menggunakan Persamaan 7 (Barron, 1948).

$\mathrm{t}=\frac{\mathrm{D}^{2}}{8 \mathrm{xCh}} \times \mathrm{Fn} \times \ln \left(\frac{1}{1-\mathrm{Uh}}\right)$

t : waktu

(tahun)

D : dia meter daerah pengaruh PVD

(m)
$\mathrm{D}=1,13 \times$ jarak PVD
(pola segiempat)
$\mathrm{D}=1,05 \mathrm{x}$ jarak PVD
(pola segitiga)

Diameter untuk pola segiempat dapat dilihat pada Gambar 4 dan untuk pola segitiga dapat dilihat pada Gambar 5.

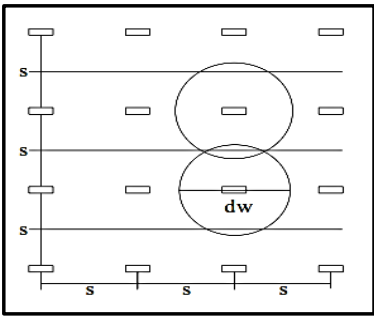

Gambar 4. Pola Segiempat Gambar 5. Pola Segitiga

Ch : koef. konsolidasi horisontal $\left(\mathrm{m}^{2} / \mathrm{thn}\right)$

$\mathrm{Ch}=2,5 \times \mathrm{Cv}$

Uh : derajat konsolidasi horisontal

Fn : fungsi hambatan akibat jarak PVD

$\mathrm{Fn}=\ln \left(\frac{\mathrm{D}}{\mathrm{dw}}\right)-\frac{3}{4}$

dw : diameter ekivalen PVD

$\mathrm{dw}=\left(\frac{2 \cdot(\mathrm{a}+\mathrm{b})}{\pi}\right)$

Derajat konsolidasi digunakan sebagai salah satu kriteria dalam menilai keefektifan pekerjaan perbaikan tanah dengan menggunakan timbunan. Terdapat dua jenis derajat konsolidasi, yaitu derajat konsolidasi tanah arah vertikal (Uv) dan derajat konsolidasi tanah arah horisontal (Uh).

Untuk menghitung nilai derajat konsolidasi tanah arah vertikal (Uv) dengan menggunakan Persamaan 11 dan 12 (Casagrande, 1983 dan Taylor, 1948). 
$\mathrm{Uv} 0 \%-60 \%=\left(2 \times \sqrt{\frac{\frac{\mathrm{Cv} \times \mathrm{t}}{\mathrm{L}^{2}}}{\pi}}\right) \times 100 \%$

$\mathrm{Uv}>60 \%=\left(100-\left(10^{\frac{1,781-\mathrm{t}}{0,933}}\right)\right) \times 100 \%$

Tv : faktor waktu vertikal

L : panjang PVD (m)

t : waktu

(tahun)

CV : koef. konsolidasi vertikal $\left(\mathrm{m}^{2} / \mathrm{thn}\right)$

Untuk menghitung nilai derajat konsolidasi tanah arah horisontal (Uh) dapat menggunakan Persamaan 13.

$\mathrm{Uh}=1-\left(\frac{1}{\exp \left(\frac{8 \times \mathrm{Chxt}}{\mathrm{D}^{2} \mathrm{x} \mathrm{Fn}}\right)}\right)$

Untuk menghitung nilai dari derajat konsolidasi rata-rata (Ur)menggunakan Persamaan 14 (Mochtar, 2000).

$\mathrm{Ur}=[1-(1-\mathrm{Uh}) \times(1-\mathrm{Uv})] \times 100 \%$

Pemasangan PVD di lapangan tidak sampai sedalam lapisan compressible dengan syarat kecepatan penurunan (rate of settlement) lapisan tanah di bawah PVD $\leq 1,50 \mathrm{~cm} /$ tahun. Untuk menghitung nilai Rate of Settlement (RoS) menggunakan Persamaan 15 (Mochtar, 2000).

$\operatorname{RoS}=\frac{\mathrm{Sc}_{\mathrm{u}}-\mathrm{PVD}}{\mathrm{t}}$

$\begin{array}{ll}\mathrm{Sc}_{\mathrm{u}-\mathrm{PVD}} & \text { : penurunan di bawah PVD } \\ & \mathrm{Sc}_{\mathrm{u}-\mathrm{PVD}}=\text { sisa } \mathrm{Sc} \mathrm{x} \mathrm{Uv} \\ \mathrm{t} & \text { : waktu u mur rencana jalan }\end{array}$

(cm)

(cm)

(tahun)

\subsection{Kenaikan Daya Dukung}

Metode perbaikan tanah dengan preloading yang dikombinasikan dengan PVD akan mempercepat waktu penurunan konsolidasi dan memampatkan tanah dasar. Preloading yang dilakukan dengan penimbunan secara bertahap mengakibatkan kenaikan tegangan air pori pada tanah lunak yang secara perlahan-lahan akan berkurang diikuti dengan meningkatknya tegangan efektif yang mengakibatkan daya dukung tanah tersebut meningkat. Besarnya kenaikan daya dukung tanah dapat dihitung dengan menghitung kenaikan kekuatan geser undrained dengan menggunakan Persamaan 16 dan 17 (Mochtar, 2000).

Untuk harga plastisitas indeks, PI tanah $<120 \%$ :

$\mathrm{Cu}=0,0737+(0,1899-0,0016 \mathrm{PI}) \sigma \mathrm{p}^{\prime}$

Untuk harga plastisitas indeks, PI tanah > $120 \%$ :

$\mathrm{Cu}=0,0737+(0,0454-0,00004 \mathrm{PI}) \sigma \mathrm{p}^{\prime}$

$\sigma \mathrm{p}_{i}{ }^{\prime}=\left\{\left(\frac{\sigma_{\mathrm{i}}{ }^{\prime}}{\mathrm{Po}^{\prime}}\right)^{\mathrm{U}} \mathrm{x} \mathrm{Po}^{\prime}\right\}-\mathrm{Po}^{\prime}$

\section{METODOLOGI}

Tahapan metodologi penelitian ditampilkan pada Gambar 6.

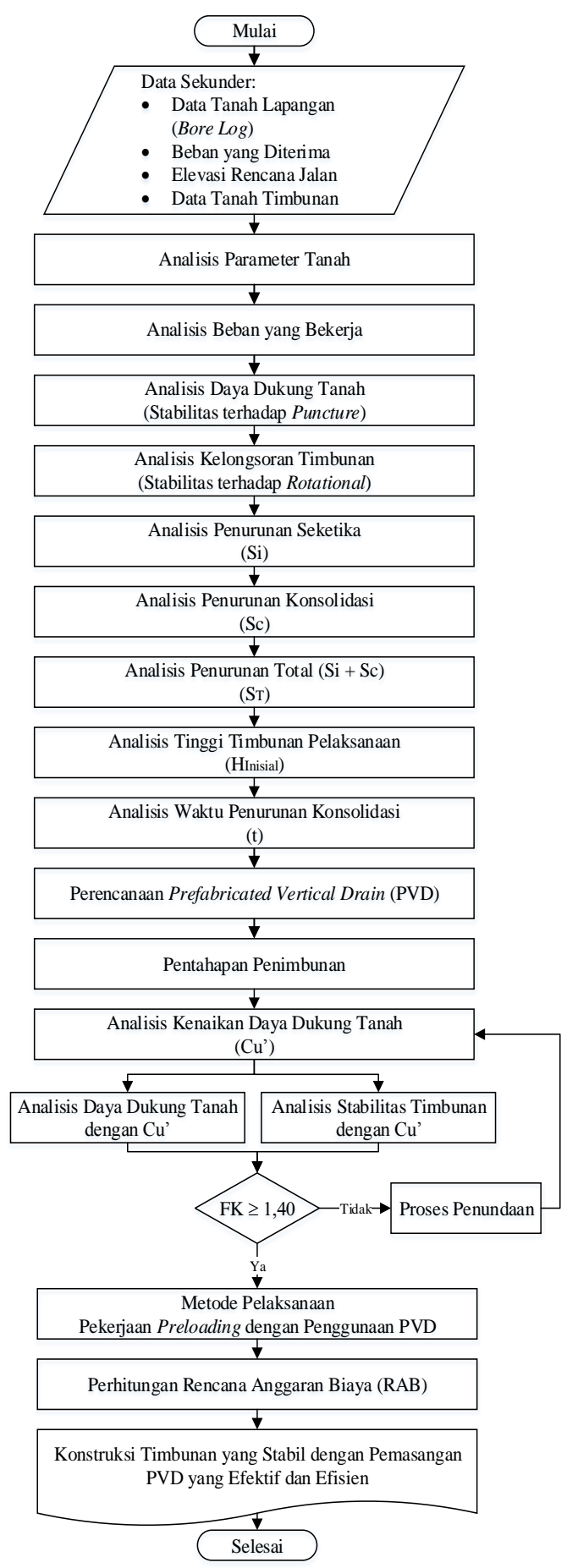

Gambar 6. Metodologi Penelitian

\section{ANALIS IS DAN PEMBAHASAN}

Stratigrafi tanah dalam perencanaan ini dapat dilihat pada Gambar 7. 


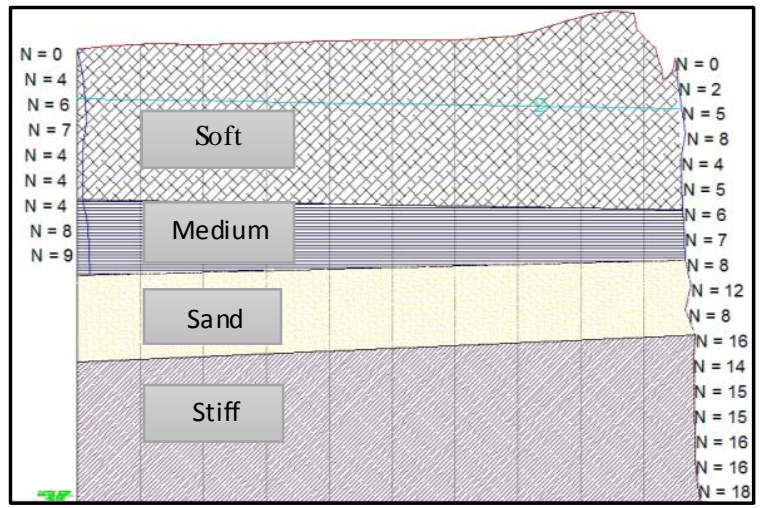

Gambar 7. Stratigrafi Tanah

\section{Data Tanah}

Data parameter tanah yang digunakan dalam perencanaan ini dapat dilihat pada Tabel 1.

Tabel 1. Data parameter tanah

\begin{tabular}{|l|c|c|}
\hline Parameter & Soft & Medium \\
\hline$\omega(\%)$ & 59,97 & 52,81 \\
$\mathrm{GS}$ & 2,70 & 2,73 \\
$\gamma_{\mathrm{m}}\left(\mathrm{t} / \mathrm{m}^{3}\right)$ & 1,62 & 1,69 \\
$\gamma_{\mathrm{sat}}\left(\mathrm{t} / \mathrm{m}^{3}\right)$ & 1,65 & 1,72 \\
$\mathrm{n}(\%)$ & 62 & 59 \\
$\mathrm{e}$ & 1,62 & 1,42 \\
$\mathrm{PI}(\%)$ & 29 & 23 \\
$\mathrm{Cv}\left(\mathrm{m}^{2} / \mathrm{tahun}\right)$ & 1,68 & 1,93 \\
$\mathrm{Cc}$ & 0,41 & 0,35 \\
$\mathrm{E}\left(\mathrm{t} / \mathrm{m}^{2}\right)$ & 400 & 900 \\
$\mu$ & 0,20 & 0,35 \\
$\phi(\mathrm{deg})$ & 0 & 0 \\
$\mathrm{Cu}\left(\mathrm{t} / \mathrm{m}^{2}\right)$ & 2,5 & 4,0 \\
\hline
\end{tabular}

\section{Data Timbunan}

$\begin{aligned} \mathrm{Cu}_{\text {Timbunan }} & =0,5 \mathrm{t} / \mathrm{m}^{2} ; \\ \phi_{\text {Timbunan }} & =25^{\circ} ; \\ \gamma_{\text {Timbunan }} & =1,7 \mathrm{t} / \mathrm{m}^{3} ; \\ \mathrm{B}_{\text {Timbunan }} & =30 \mathrm{~m} ; \mathrm{V}: \mathrm{H}=1: 2 .\end{aligned}$

\section{Beban yang Bekerja}

$\mathrm{H}_{\text {Final Timbunan }}=8,1 \mathrm{~m} ;$
$\mathrm{H}_{\text {Preload Lalu Lintas }}=0,3 \mathrm{~m} ;$
$\mathrm{H}_{\text {Preload Perkerasan }}=0,5 \mathrm{~m} ;$
$\mathrm{H}_{\text {Total }}=8,9 \mathrm{~m}$.

Daya Dukung Tanah

Hasil analisis daya dukung tanah (stabilitas terhadap puncture) dengan menggunakan Persamaan 1 dapat dilihat pada Tabel 2 .

Tabel 2. Analisis daya dukung tanah

\begin{tabular}{|c|c|}
\hline $\mathrm{H}(\mathrm{m})$ & Faktor Keamanan \\
\hline 2,0 & 3,78 \\
4,0 & 1,89 \\
6,0 & 1,26 \\
8,0 & 0,95 \\
10,0 & 0,76 \\
12,0 & 0,63 \\
\hline
\end{tabular}

Stabilitas Timbunan terhadap Rotational

Hasil analisis stabilitas timbunan (stabilitas terhadap rotational) dengan menggunakan bantuan software GeoStudio 2007 Slope/W dapat dilihat pada Tabel 3.

Tabel 3. Analisis Daya Dukung Tanah

\begin{tabular}{|c|c|}
\hline $\mathrm{H}(\mathrm{m})$ & Faktor Keamanan \\
\hline 2,0 & 3,02 \\
4,0 & 1,77 \\
6,0 & 1,28 \\
8,0 & 1,02 \\
10,0 & 0,86 \\
12,0 & 0,75 \\
\hline
\end{tabular}

Hasil analisis daya dukung tanah dan stabilitas timbunan dibuatkan ke dalam bentuk grafik yang dapat dilihat pada Gambar 8. Untuk mengetahui tinggi timbunan maksimum dengan nilai $\mathrm{FK} \approx 1,40$.

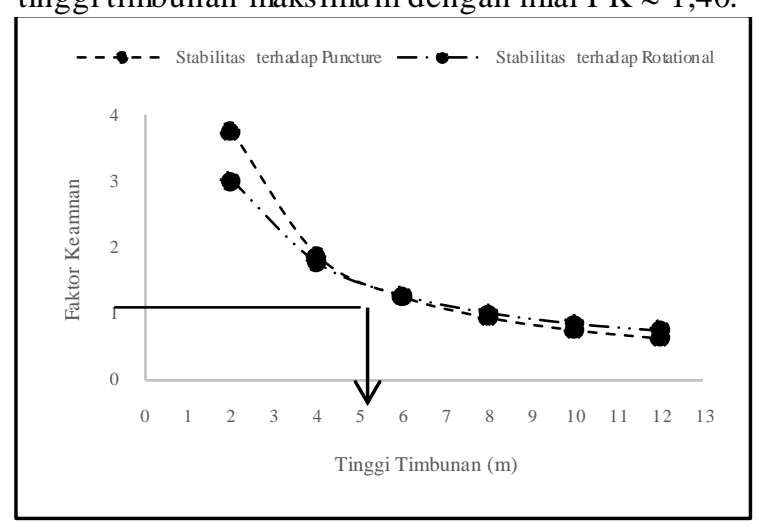

Gambar 8. Nilai Faktor Keamanan

$\mathrm{H}_{\text {Kritis Timbunan }}=5 \mathrm{~m}$. Tinggi timbunan maksimum yang mampu ditahan oleh tanah dasar dengan nilai $\mathrm{FK} \approx 1,40$ adalah $5 \mathrm{~m}$.

\section{Penurunan Seketika (Si)}

$\mathrm{E}_{\text {Soft }}=\frac{400}{\left(1-\frac{2(0,20)^{2}}{1-0,20}\right)}=444,44 \mathrm{t} / \mathrm{m}^{2}$

$\mathrm{Si}_{\text {Soft }}=(15,13+1,36) \times\left(\frac{10}{444,44}\right)=0,371 \mathrm{~m}$

$\mathrm{E}_{\text {Medium }}=\frac{900}{\left(1-\frac{2(0,35)^{2}}{1-0,35}\right)}=1444,4 \mathrm{t} / \mathrm{m}^{2}$

$\mathrm{Si}_{\text {Medium }}=(15,13+1,36) \times\left(\frac{8,0}{1444,44}\right)=0,091 \mathrm{~m}$

$\mathrm{Si}_{\text {Total }}=0,371+0,091=0,462 \mathrm{~m}$

Penurunan Konsolidasi (Sc)

Perhitungan penurunan konsolidasi (Sc) menggunakan Persamaan 3. Dihitung perlapis $(\mathrm{h}=1$ $\mathrm{m})$. Tinggi timbunan $8,9 \mathrm{~m}$ mengalami penurunan konsolidasi sedalam $1,342 \mathrm{~m}$.

Penurunan Total $\left(\mathbf{S}_{\mathbf{T}}\right)$

$\mathrm{Si}+\mathrm{Sc}=0,462+1,342=1,8 \mathrm{~m}$ 
Tinggi Timbunan Pelaksanaan $\left(\mathrm{H}_{\text {Inisial }}\right)$

Perhitungan tinggi timbunan pelaksanaan menggunakan Persamaan 6. Untuk menentukan tinggi timbunan pada saat pelaksanaan akhir di lapangan dapat dilihat pada Gambar 9.

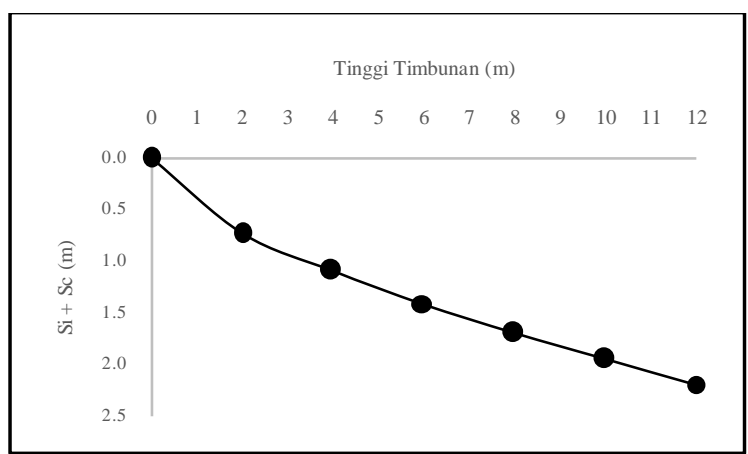

Gambar 9. Tinggi Timbunan Pelaksanaan

$\mathrm{H}_{\mathrm{A}}=8,9 \mathrm{~m} \rightarrow \mathrm{S}_{\mathrm{T}}=1,80 \mathrm{~m} \rightarrow \mathrm{H}_{\text {Inisial }}=10,7 \mathrm{~m}$

$\mathrm{H}_{\mathbf{B}}=10,7 \mathrm{~m} \rightarrow \mathrm{S}_{\mathrm{T}}=2,10 \mathrm{~m} \rightarrow \mathrm{H}_{\text {Inisial }}=11,0 \mathrm{~m}$

$\mathrm{H}_{\mathrm{C}}=11,0 \mathrm{~m} \rightarrow \mathrm{S}_{\mathrm{T}}=2,122 \mathrm{~m}$

Selisih antara penurunan kondisi $\mathrm{C}$ dengan kondisi $\mathrm{B}$ adalah $0,022 \mathrm{~m}$. Selisih penurunan ini dapat diterima karena nilainya mendekati nol yang artinya tidak akan terjadi lagi penurunan. Jadi tinggi timbunan pada saat pelaksanaan akhir di lapangan adalah $11,0 \mathrm{~m}$

\section{Waktu Penurunan Konsolidasi}

Waktu penurunan konsolidasi yang terjadi adalah ketika derajat konsolidasi mencapai $90 \%$

$\mathrm{t}=\frac{\mathrm{TV} \times \mathrm{H}_{\mathrm{Dr}}{ }^{2}}{\mathrm{Cv}}=\frac{0,848 \times 9,0^{2}}{1,78}=38,49$ tahun

\section{Perencanaan PVD Pola Segitiga}

Perencanaan PVD pola segitiga dilakukan dengan jarak $1,0 \mathrm{~m} ; 1,1 \mathrm{~m} ; 1,2 \mathrm{~m} ; 1,3 \mathrm{~m} ; 1,4 \mathrm{~m}$; dan $1,5 \mathrm{~m}$. Hasil perhitungan dibuatkan ke dalam bentuk grafik hubungan antara waktu konsolidasi dengan derajat konsolidasi dapat dilihat pada Gambar 10.

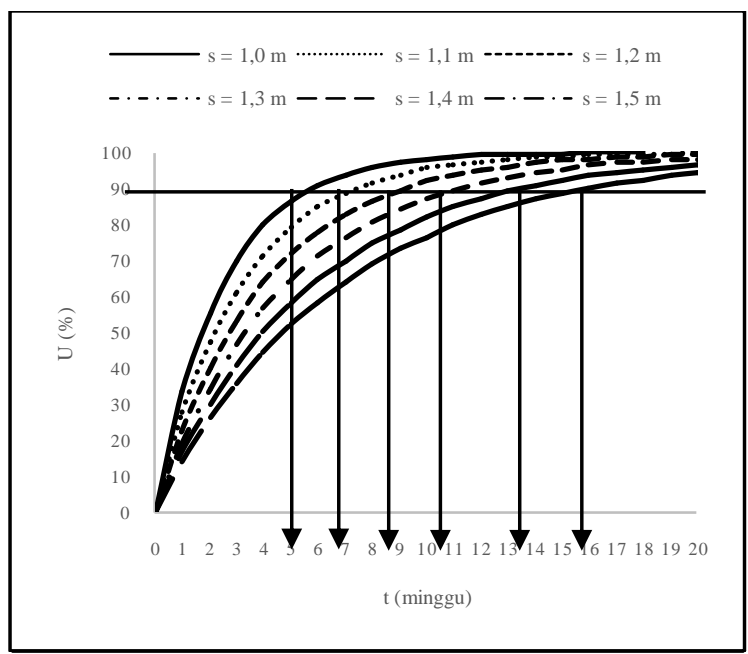

Gambar 10. PVD Pola Segitiga

$$
\begin{array}{ll}
\mathrm{s}=1,0 \mathrm{~m} & \rightarrow \mathrm{t}=6 \text { minggu } \\
\mathrm{s}=1,1 \mathrm{~m} & \rightarrow \mathrm{t}=7,4 \operatorname{ming} \mathrm{u} \\
\mathrm{s}=1,2 \mathrm{~m} & \rightarrow \mathrm{t}=9 \operatorname{minggu} \\
\mathrm{s}=1,3 \mathrm{~m} & \rightarrow \mathrm{t}=11 \operatorname{minggu} \\
\hline \mathrm{s}=1,4 \mathrm{~m} & \rightarrow \mathrm{t}=14 \operatorname{minggu} \\
\mathrm{s}=1,5 \mathrm{~m} & \rightarrow \mathrm{t}=16 \operatorname{minggu}
\end{array}
$$

\section{Perencanaan PVD Pola Segiempat}

Perencanaan PVD pola segiempat dilakukan dengan jarak $1,0 \mathrm{~m} ; 1,1 \mathrm{~m} ; 1,2 \mathrm{~m} ; 1,3 \mathrm{~m} ; 1,4 \mathrm{~m}$; dan $1,5 \mathrm{~m}$. Hasil perhitungan dibuatkan ke dalam bentuk grafik hubungan antara waktu konsolidasi dengan derajat konsolidasi dapat dilihat pada Gambar 11.

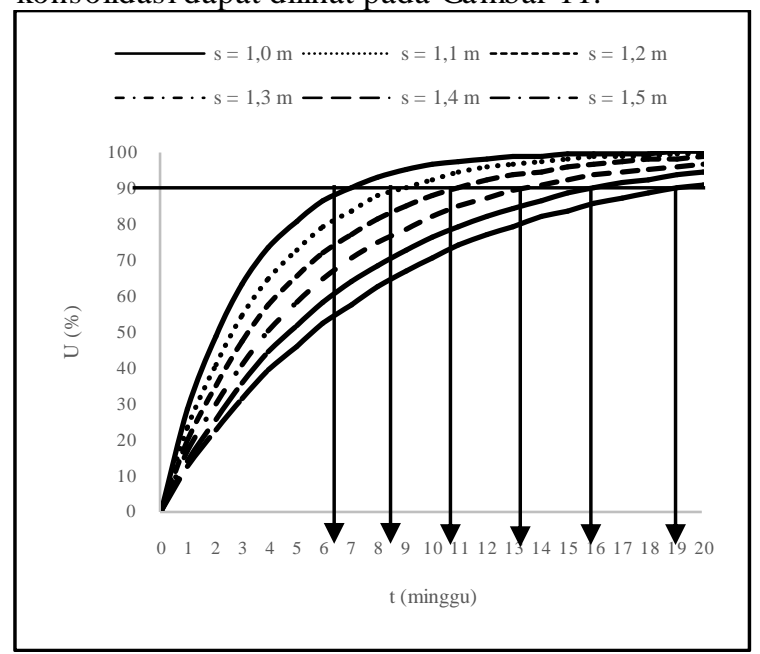

Gambar 11 PVD Pola Segiempat

\begin{tabular}{ll}
$\mathrm{s}=1,0 \mathrm{~m}$ & $\rightarrow \mathrm{t}=7$ minggu \\
$\mathrm{s}=1,1 \mathrm{~m}$ & $\rightarrow \mathrm{t}=9$ minggu \\
\hline $\mathrm{s}=1,2 \mathrm{~m}$ & $\rightarrow \mathrm{t}=11$ minggu \\
$\mathrm{s}=1,3 \mathrm{~m}$ & $\rightarrow \mathrm{t}=13,5$ minggu \\
$\mathrm{s}=1,4 \mathrm{~m}$ & $\rightarrow \mathrm{t}=16$ minggu \\
$\mathrm{s}=1,5 \mathrm{~m}$ & $\rightarrow \mathrm{t}=19$ minggu
\end{tabular}

Panjang Pemasangan PVD di Lapangan

\begin{tabular}{|c|c|c|c|c|c|c|c|c|c|}
\hline \multicolumn{3}{|c|}{$\begin{array}{l}\text { Tebal Lapisan } \\
\text { Terkonsolidasi }\end{array}$} & \multicolumn{3}{|c|}{$\begin{array}{l}\text { Settlement Akibat } \\
\text { Timbunan }\end{array}$} & \multicolumn{3}{|c|}{ Setelah 20 tahun } & \multirow[b]{2}{*}{$\begin{array}{l}\text { Rate of } \\
\text { Settlement } \\
\text { (cm tahun) }\end{array}$} \\
\hline $\begin{array}{c}\text { Total } \\
(\mathrm{m})\end{array}$ & $\begin{array}{c}\text { L } \\
\text { PVD } \\
\text { (m) }\end{array}$ & $\begin{array}{c}\mathrm{di} \\
\text { bawah } \\
\text { PVD } \\
\text { (m) } \\
\end{array}$ & $\begin{array}{l}\text { Total } \\
(\mathrm{m})\end{array}$ & $\begin{array}{c}\text { Sedalam } \\
\text { PVD } \\
\text { (m) }\end{array}$ & $\begin{array}{l}\text { Sisa } \\
(\mathrm{m})\end{array}$ & Tv & Uv & $\begin{array}{c}\mathrm{Sc} \\
(\mathrm{m})\end{array}$ & \\
\hline 18 & 1 & 17 & 1,499 & 0,217 & 1,282 & 0,110 & 0,37 & 0,480 & 2,401 \\
\hline 18 & 2 & 16 & 1,499 & 0,366 & 1,134 & 0,110 & 0,37 & 0,425 & 2,123 \\
\hline 18 & 3 & 15 & 1,499 & 0,484 & 1,015 & 0,110 & 0,37 & 0,380 & 1,901 \\
\hline 18 & 4 & 14 & 1,499 & 0,585 & 0,915 & 0,110 & 0,37 & 0,343 & 1,713 \\
\hline 18 & 5 & 13 & 1,499 & 0,676 & 0,824 & 0,110 & 0,37 & 0,308 & 1,542 \\
\hline 18 & 6 & 12 & 1,499 & 0,762 & 0,737 & 0,110 & 0,37 & 0,276 & 1,381 \\
\hline 18 & 7 & 11 & 1,499 & 0,844 & 0,655 & 0,110 & 0,37 & 0,245 & 1,227 \\
\hline 18 & 8 & 10 & 1,499 & 0,922 & 0,577 & 0,110 & 0,37 & 0,216 & 1,081 \\
\hline 18 & 9 & 9 & 1,499 & 0,997 & 0,503 & 0,110 & 0,37 & 0,188 & 0,941 \\
\hline 18 & 10 & 8 & 1,499 & 1,068 & 0,431 & 0,110 & 0,37 & 0,162 & 0,808 \\
\hline 18 & 11 & 7 & 1,499 & 1,131 & 0,369 & 0,110 & 0,37 & 0,138 & 0,690 \\
\hline 18 & 12 & 6 & 1,499 & 1,191 & 0,309 & 0,110 & 0,37 & 0,116 & 0,578 \\
\hline 18 & 13 & 5 & 1,499 & 1,248 & 0,251 & 0,110 & 0,37 & 0,094 & 0,471 \\
\hline 18 & 14 & 4 & 1,499 & 1,303 & 0,197 & 0,110 & 0,37 & 0,074 & 0,368 \\
\hline 18 & 15 & 3 & 1,499 & 1,355 & 0,144 & 0,110 & 0,37 & 0,054 & 0,270 \\
\hline 18 & 16 & 2 & 1,499 & 1,405 & 0,094 & 0,110 & 0,37 & 0,035 & 0,176 \\
\hline 18 & 17 & 1 & 1,499 & 1,453 & 0,046 & 0,110 & 0,37 & 0,017 & 0,086 \\
\hline 18 & 18 & 0 & 1,499 & 1,499 & 0,000 & 0,110 & 0,37 & 0,000 & 0,000 \\
\hline
\end{tabular}
Penentuan panjang pemasangan PVD di lapangan berdas arkan nilai rate of settlement $\leq 1,50 \mathrm{~cm} /$ tahun, dapat dilihat pada Tabel 4.

Tabel 4. Penentuan Panjang PVD di Lapangan 


\section{Kenaikan Daya Dukung Tanah}

Tinggi timbunan maksimum yang dapat ditahan oleh tanah dasar setinggi $5 \mathrm{~m}$, diperlukan perhitungan kenaikan daya dukung tanah $\left(\mathrm{Cu}^{\prime}\right)$ agar tahapan penimbunan selanjutnya dalam dilaksanakan. Tiap tahap penimbunan dilakukan perhitungan kenaikan daya dukung tanah $\left(\mathrm{Cu}^{\prime}\right)$. Hasil dari perhitungan kenaikan daya dukung tanah untuk tiap tahap penimbunan dapat dilihat pada Tabel 5.

Tabel 5. Nilai Cu' tiap Tahap Penimbunan

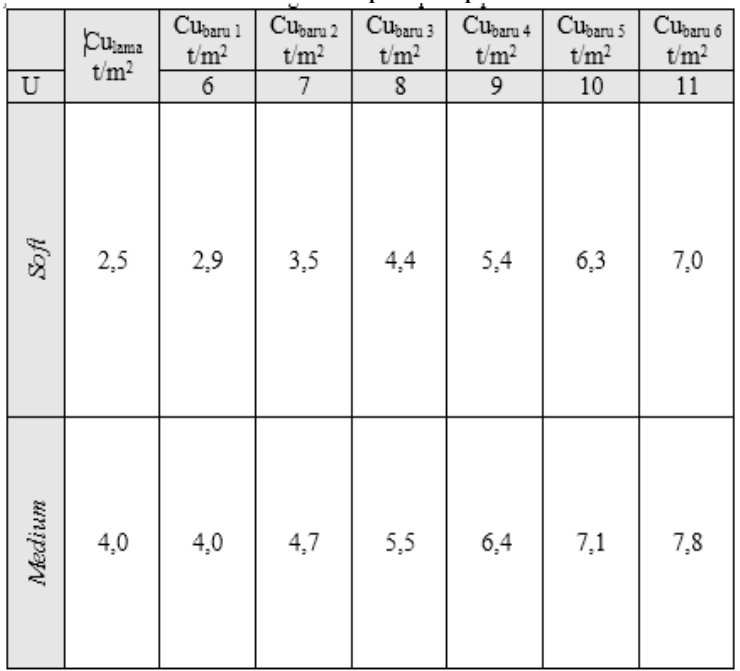

Analisis daya dukung tanah dan stabilitas timbunan dilakukan dengan menggunakan nilai $\mathrm{Cu}$ ' tiap tahap penimbunan untuk mengetahui apakah tahapan penimbunan dapat dilaksanakan atau dibutuhkan proses penundaan. Hasil nilai faktor keamanan untuk tiap tahap penimbunan dapat dilihat pada Tabel 6 .

Tabel 6. Nilai FK tiap Tahap Penimbunan

\begin{tabular}{|c|c|c|}
\hline $\begin{array}{c}\text { Tinggi Timbunan } \\
(\mathrm{m})\end{array}$ & $\begin{array}{c}\text { FK Daya Dukung } \\
\text { Tanah }\end{array}$ & $\begin{array}{c}\text { FK Stabilitas } \\
\text { Timbunan }\end{array}$ \\
\hline 6 & 1,45 & 1,46 \\
\hline 7 & 1,53 & 1,53 \\
\hline 8 & 1,66 & 1,63 \\
\hline 9 & 1,81 & 1,58 \\
\hline 10 & 1,89 & 1,52 \\
\hline 11 & 1,93 & 1,51 \\
\hline
\end{tabular}

\section{Penurunan akibat Penimbunan Bertahap}

Setiap tahap penimbunan akan mengalami penurunan (Gambar 12) dan harus diperhitungkan untuk mengetahui lamanya waktu yang diperlukan untuk mencapai penurunan sebesar 2,122 m. Untuk memudahkan dalam mengetahui waktu yang diperlukan untuk mencapai penurunan 2,122 m menggunakan bantuan grafik hubungan antara tinggi timbunan dan penurunan dengan waktu akibat yang dapat dilihat pada Gambar 13.

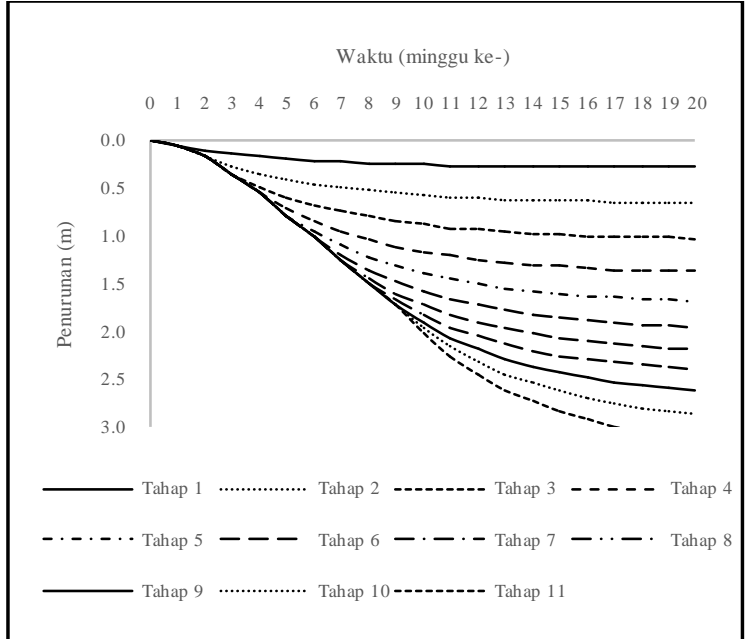

Gambar 12. Penurunan Tiap Tahap Penimbunan

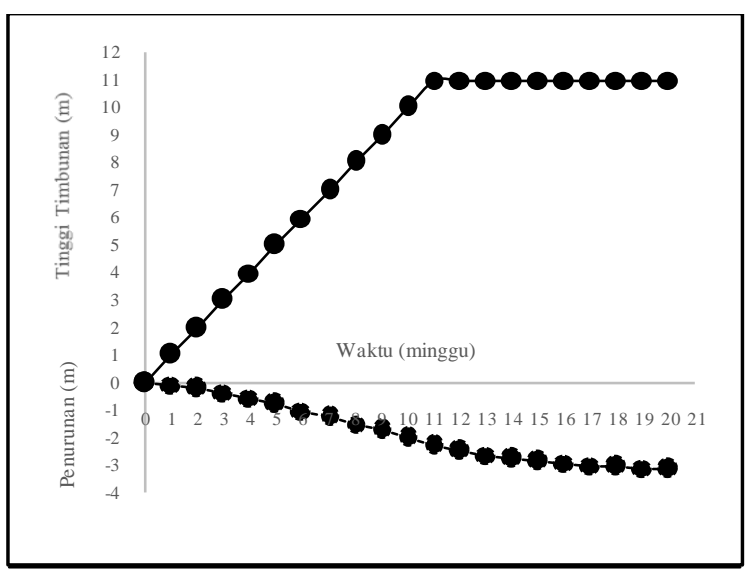

Gambar 13. Penurunan akibat Penimbunan Bertahap

Untuk mencapai penurunan sedalam 2,122 m membutuhkan waktu tunggu selama 11 minggu dari awal penimbunan.

\section{Metode Pelaksanaan}

1) persiapan lahan, alat, dan material;

2) persiapan lantai kerja;

3) pemberian tanda titik pe masangan PVD;

4) Pemasangan instrumen geoteknik

5) instalasi mandrel dan masdrel pada crawler crane;

6) pemasangan anchor plate (sepatu pelat);

7) pemasangan dan penarikan mandrel;

8) pemotongan dan atau penyambungan PVD;

9) penimbunan bertahap; dan

10) pengujian kepadatan timbunan.

\section{Rencana Anggaran Biaya}

Rencana anggaran biaya terdiri dari pekerjaan timbunan pasir, pemasangan PVD, dan pekerjaan timbunan pilihan yang dapat dilihat pada Tabel 7. 
Tabel 7. Rencana Anggaran Biaya

\begin{tabular}{|c|l|c|c|r|r|}
\hline No & Uraian Pekerjaan & Satuan & $\begin{array}{c}\text { Perkiraann } \\
\text { Kuantitas }\end{array}$ & $\begin{array}{c}\text { Harga Satuann } \\
\text { (Rupiah) }\end{array}$ & $\begin{array}{c}\text { Jumlah } \\
\text { (Rupiah) }\end{array}$ \\
\hline & & & & & \\
\hline I & Timbunan Pasir & $\mathrm{m}^{3}$ & 3024 & 102.358 & 309.529 .257 \\
\hline II & Pemasangan PVD & $\mathrm{m}$ & 12121 & 4.009 & 48.595 .191 \\
\hline III & Timbunan Pilihan & $\mathrm{m}^{3}$ & 29499 & 104.691 & 3.088 .224 .868 \\
\hline \multicolumn{7}{|c|}{ Jumlah Harga Pekerjaan } & 3.446 .349 .317 \\
\hline
\end{tabular}

\section{KES IMPULAN}

Kesimpulan dari analisis dan pembahasan pada perencanaan ini adalah sebagai berikut:

1. Elevasi eksisting $=6,30 \mathrm{~m}$; elevasi rencana $=$ $14,41 \mathrm{~m}$. Tinggi timbunan rencana $=8,10 \mathrm{~m}$.

2. Permasalahan yang terjadi adalah daya dukung tanah dasar rendah, yakni tanah dasar hanya mampu menahan beban timbunan setinggi 5,0 m.

3. Permasalahan selanjutnya adalah penurunan yang terjadi sedalam $2,122 \mathrm{~m}$ dengan waktu konsolidasi $90 \%$ selama 38,49 tahun. Tinggi timbunan pada saat pelaksanaan akhir adalah $11,0 \mathrm{~m}$.

4. PVD yang digunakan yaitu tipe Ce-Teau Drain CT-882 dengan lebar (a) $100 \mathrm{~mm}$ dan tebal (b) $40 \mathrm{~mm}$ sedalam $10 \mathrm{~m}$ dari muka tanah dengan pola segiempat berjarak $1,2 \mathrm{~m}$. Waktu yang dibutuhkan untuk mencapai waktu konsolidasi (U) $90 \%$ adalah 11 minggu.

5. Penimbunan dilakukan bertahap dengan kecepatan penimbunan $1 \mathrm{~m}$ perminggu. Tahapan penimbunan yang dilakukan adalah sebanyak 11 kali dan menghasilkan peningkatan daya dukung tanah dasar (Cu'). Tinggi kritis timbunan $\left(\mathrm{H}_{\mathrm{Cr}}\right)$ adalah $5 \mathrm{~m}$ dengan faktor keamanan rencana sebesar 1,40. Pada awal penimbunan nilai $\mathrm{Cu}$ adalah2,5 t/ $\mathrm{m}^{2}$ dan nilai $\mathrm{Cu}$ naik menjadi sebesar $7,0 \mathrm{t} / \mathrm{m}^{2}$ pada akhir tahap penimbunan.

6. Waktu yang dibutuhkan untuk mencapai penurunan total sebesar 2,122 m denganmenggunakan metode preloading yang diko mbinasikan PVD adalah 11 minggu.

7. Metode pelaksanaan pekerjaan PVD adalah sebagai berikut:

a. persiapan lahan, alat, dan material;

b. persiapan lantai kerja;

c. pemberian tanda titik pe masangan PVD;

d. Pemasangan instrumen geoteknik;

e. instalasi mandrel dan masdrel pada crawler crane;

f. pemasangan anchor plate (sepatu pelat);

g. pemasangan dan penarikan mandrel;

h. pemotongan dan atau penyambungan PVD;

i. penimbunan bertahap; dan

j. pengujian kepadatan timbunan.

8. Biaya yang dibutuhkan untuk melakukan pekerjaan penimbunan dan pemasangan PVD sesuai dengan desain yang direncanakan adalah sebesar Rp. 3.446.349.317,--.

\section{DAFTAR PUS TAKA}

2013. Analisis Harga Satuan Pekerjaan (AHSP) Bidang Pekerjaan Umum, Kementrian Pekerjaan Umum.

2015. Jurnal Harga Satuan Bahan Bangunan Konstruksi dan Interior Edisi 34 Tahun 2015. Pandu Bangun Persada Nusantara.

Amalia, Dewi. 2008. Perencanaan Reklamasi pada Lapangan Penumpukan Terminal Peti Kemas II di Teluk Lampng, Pelabuhan Tanjung Perak, Surabaya. Laporan Penelitian. Jurusan Teknik Sipil Institut Teknologi Sepuluh Nopember.

Amalia, Dewi, Dkk. 2007. Pekerjaan Tanah pada Proyek Pembangunan Jalan Tol SurabayaMojokerto. Laporan Kerja Praktik. Jurusan Teknik Sipil Institut Teknologi Sepuluh Nopember.

Astuti, Santi Widi. 2012. Perancangan Penanggulangan Kelongsoran pada Struktur Timbunan Oprit Jembatan SeiEkang Kabupaten Bintang Provinsi Kepulauan Riau Menggunakan Prefabricated Vertical Drain. Laporan Penelitian. Jurusan Teknik Sipil Politeknik Negeri Bandung.

Das, Braja M, Dkk. 1994. Mekanika Tanah (Prinsipprinsip Rekayasa Geoteknis). Jilid 1. Penerbit Erlangga. Jakarta.

Das, Braja M, Dkk. 1994. Mekanika Tanah (Prinsipprinsip Rekayasa Geoteknis). Jilid 2. Penerbit Erlangga. Jakarta.

Elisa. 2014. Desain Peningkatan Daya Dukung Tanah Lunak pada Pembangunan Jalan Akses PLTU Ketapang, Kalimantan Barat. Laporan Penelitian. Jurusan Teknik Sipil Politeknik Negeri Bandung.

Fahmi, Baharudin. 2013. Konsolidasi Tanah. http://jejaks amudera.b logs pot.com/2013/09/ko nsolidasi-tanah.html. Diakses pada 22 Juli 2015 pukul 4:40.

Junditiawan, Awan. 2014. Kasus Kurangnya Daya Dukung Tanah Dasar (Subgrade) Pada Pekerjaan Penambahan Lajur Ruas Cibinong-Sentul Selatan km 27+500 s/d km 37+000 Jalur A pada Jalan Tol Jagorawi. Laporan Studi Kasus. Jurusan Teknik Sipil Politeknik Negeri Bandung.

Juniarto. 2011. Analisa Waktu Penurunan Tanah dengan Kombinasi Metode Preloading dan Prefabricated Vertical Drain (PVD) antara Pola Segitiga dan Persegi pada Perbaikan 
Vol. 21, No.1, Maret 2019

Tanah. Penerbit Lembaga Penelitian Universitas Gunadarma.

Mochtar. B, Indrasurya, 2000. Teknik Perbaikan Tanah dan Alternatif Perencanaan pada Tanah Bermasalah (Problematic Soils). Surabaya: Jurusan Teknik Sipil - FTSP, ITS.

Unggul, PT. Teknindo Geosistem. 2015. Prinsip Dasar Metode Perbaikan Tanah Metode Preloading dengan PVD.

Wahyudi, Herman. 1999. Teknik Reklamasi. Surabaya: Jurusan Teknik Sipil - FTSP, ITS.

Yunias, Lishia. 2010. Analisa Balik Parameter Desain Preloading dengan Vertical Drains - Studi Kasus Perbaikan Tanah PT. Pupuk Kaltim di Bontang. Laporan Skripsi. Jurusan Teknik Sipil Universitas Bina Nusantara. 